\title{
The Long-term Development Strategy to Enhance the International Competitiveness of Regional Visual Effects Cluster
}

\author{
Pinfang Yuan ${ }^{1}$, MyungHee $\mathrm{Han}^{2}$ and Tea Soo Yun ${ }^{3}$ \\ Division of Visual Contents, Graduate School \\ Dongseo University, Busan, Korea \\ fever12ypf@gmail.com ${ }^{1}$,renoman@dongseo.ac.kr ${ }^{2}$, tsyun@dongseo.ac.kr ${ }^{3}$
}

\begin{abstract}
In recent years, the global film market scale has been growing up year by year. As an important pillar industry of the digital content, visual effects boost the local economy greatly. Therefore, many countries and regions attach great importance to them and take them as the key supported industry. This paper, based on Porter's Diamond Model, selects such industrial clusters of the most internationally-competitive effects Hollywood, London and Wellington as the research objects, investigates the status quo of the world visual effects industry and comparatively analyses the factors of limiting industrial development, looking for long-term sustainable development strategy which can break the bottleneck of regional visual effects industry, and exploring branding strategies to strengthen regional effects industries in global competition.
\end{abstract}

Keywords: Visual Effects, Regional Cluster, Long-term Strategy, Hollywood, London, New Zealand, Diamond Model

\section{Introduction}

With the trend of globalization and technological progress, visual effects industry has achieved the global division of labor in order to maximize profits. What's more, through outsourcing in the form of products and services, visual effects have broken through the geographical restriction so that the production can be processed anywhere. In recent decades, in addition to Hollywood with a long-standing leadership position in the industry, other regions also highlight the industrial clusters of competitive visual effects, such as the visual effects location of Lord of the Rings ----Wellington in New Zealand, and SOHO where the visual effects of Harry Potter are produced in London. Besides, Australia, Canada, South Korea and such countries with lower cost labor as China and India actively seize the international market.

At present, such large budget film projects are generally co-produced by several facilities, one of those takes the charge and divides the labor and quantity to outsource to other facilities. It is due to the size restriction that few facilities have the ability to independently complete such a big project alone. Also the industry characteristics make it necessary for visual effects facilities to mutually cooperate and aggregate. Therefore, the industrial cluster of visual effects is the best shortcut to upgrade the productivity. Only through cooperation and competition of related businesses within the industrial cluster can the production scale of regional effects industry be expanded at the fastest speed, can the industrial technology be stimulated and can the international competitiveness of local industrial visual effects be enhanced. To stand out in the global competition, it needs to establish a brand of regional visual effects industry and make use of regional advantages to seek characteristic competitive strategies different from those of other regions. 


\section{The Status Quo of the Global Visual Effects Industry}

According to the related statistics, from 2008 to 2012, the animation market scale value has increased from $\$ 13$ billion to $\$ 17$ billion. Besides, film, television and advertising also have substantially grown. A report expects that by 2017 , the animation market scale will maintain an annual growth of 5per cent while the annual growth rate of film, television, advertising will reach 3.6per cent, 4.3per cent and 4.8per cent respectively. All these are the major markets of these visual effects industries. Compared with the traditional content industries, such as publishing and music etc, visual effects market has a promising outlook, which also helps to motivate various countries to develop visual effects industries.

Among them, as the birthplace of world visual effects industry, Hollywood in the United States, has been regarded as the industry benchmark, but since the late 1990s, because of the tax incentives and low cost labor of other countries, film studios have started to send projects overseas for production in order to cut costs, which changed the long-term monopoly in Hollywood so that the competition of effects industry also started to become international. At the same time, Wellington attracted remarkable attention because of the hit of Lord of the Rings and Hobbits, also the growing London has become one of the most internationally competitive regions with the Harry Potter series.

\subsection{Hollywood}

Compared with other traditional sectors within the film production system of the United States, like photography, editing and sound, visual effects field has experienced tremendous changes. In the over 100-year-old film history, the technology of digital visual effects is actual less than 40 years, but with the development of computer and digital technology, as well as the diversification of film genres, visual effects have made remarkable achievements in variety of films.

In the 1970s, Jaws (1975) and Star Wars created the beginning of using CG technology to produce visual effects. Since 1975 when the director George Lucas established ILM in order to make Star Wars, ILM has placed a new milestone for film production and also contributed to the proportion increase the visual effects production in films. ILM, which was responsible for the visual effects of Who Framed Roger Rabbit, set a new standard for combining real footage and CG animation synthesis, combined with which the visual effects were officially introduced. Entering 1990s, after Pixar' Toy Story achieved success in 1995, a large number of 3D animated films began to appear and the successful Shrek series of the Dreamworks also created the highest grossing of CG animated film. In addition, the Titanic in 1997 also pushed the visual effects to the height of a large-scale visual -effect works, laying the foundation for Hollywood, the Kingdom of visual effects.

As the center of world cinema, Hollywood gathers a large number of related facilities of visual effects. However, facing with the fierce Hollywood's inner competition and tax incentives of other regions overseas that lead to the outflow of many Hollywood projects, Hollywood visual effects facilities are facing a management crisis. From 2003 2013, 21 visual effects companies closed or filed for bankruptcy. Back to the relevant statistics in 2008 when the top ten world's leading CG facilities accounted for six in Hollywood, but until now two of the six facilities have formally declared bankruptcy, namely, Digital Domain co-founded by the director of Avatar James Cameron and Rhythm \& Hues right after awarding the Academy Award for Best Visual Effects for Life of Pi.

\subsection{London}

UK's visual effects manpower and facilities are concentrated mainly in London. Eight of the world class visual effects studios are located in SOHO cluster. Of them, "Framestore" that has won the 86th Academy Award (Visual Effect), "MPC" that 
produced "Harry Potter" and "Double Negative" that produced "Inception" are gathered within five-minute`s walking distance. In the case of "Gravity", pre-biz in pre-production, main production and post-production have been completed in SOHO. Small visual effects facilities have joined $\mathrm{SOHO}$ cluster, which formed an overall industrial chain. As a result, visual effects production scale and capability has improved significantly. Despite such reality that even a world class visual effects company is hardly capable of performing all the visual effects works for one film. But the whole production process of one blockbuster film could be localized within SOHO. Furthermore, visual effects facilities in SOHO can share resources, manpower and visual effects projects owing to this geographical concentration while also competing with each other. In return it increases the competitiveness of the UK`s visual effects industry. London as a global center of creative industries, many content creation businesses are located there, and creative talents from all over the world are flocking into London. UK's creative industry policies have been implemented since 1997, causing a great impact across the world. Affluent creative manpower and cultural background made great contribution to the visual effects industry in London.

\subsection{Wellington}

Since 2000s, New Zealand which was dominated by agricultural output has rapidly grown into one of the most competitive countries within visual effects industry through the Lord of the Rings, King Kong, Avatar and such series of films. Weta Digital has taken charge of the visual effects work of all these film that pushes New Zealand to the forefront of film and television industry. Driven by Lord of the Rings, Weta gradually expanded and formed an industrial cluster focusing on visual effects industry. As a consequence, Wellington, a small city where Weta is located in, has gradually developed into a hot place gathering with visual effects facilities and talents from all over the world.

Although much of physical shooting remains tethered to Los Angeles and New York, because production costs to ship films overseas would be uneconomical. But visual effects can easily be sent overseas, where film studios can benefit from favorable tax structures. In 2013 alone, "Wellywood's" Weta Digital provided effects work on blockbusters like The Hobbit, Iron Man 3, and The Wolverine.

Now New Zealand mainly undertakes film projects from US and highly depends on overseas markets. Such a single target market undoubtedly could put New Zealand in the business risk, which is likely to be influenced once the Hollywood policy or economy changes.

\section{The Diamond Model of Industrial Cluster}

Porter`s Diamond Model of cluster analysis includes four interrelated components and two exogenous parameters that contribute to the success or failure of an industry in global competition. Porter argues that nations are most likely to succeed in industries or industry segments where the national 'diamond' is the most favorable. The four interrelated components are factor conditions, demand conditions, related and supporting industries, and firm strategy, structure, and rivalry, other two parameters are government and chance. Porter also stressed that elements in the diamond model are interdependent, any element of the industry would influence the potential of upgrading. 


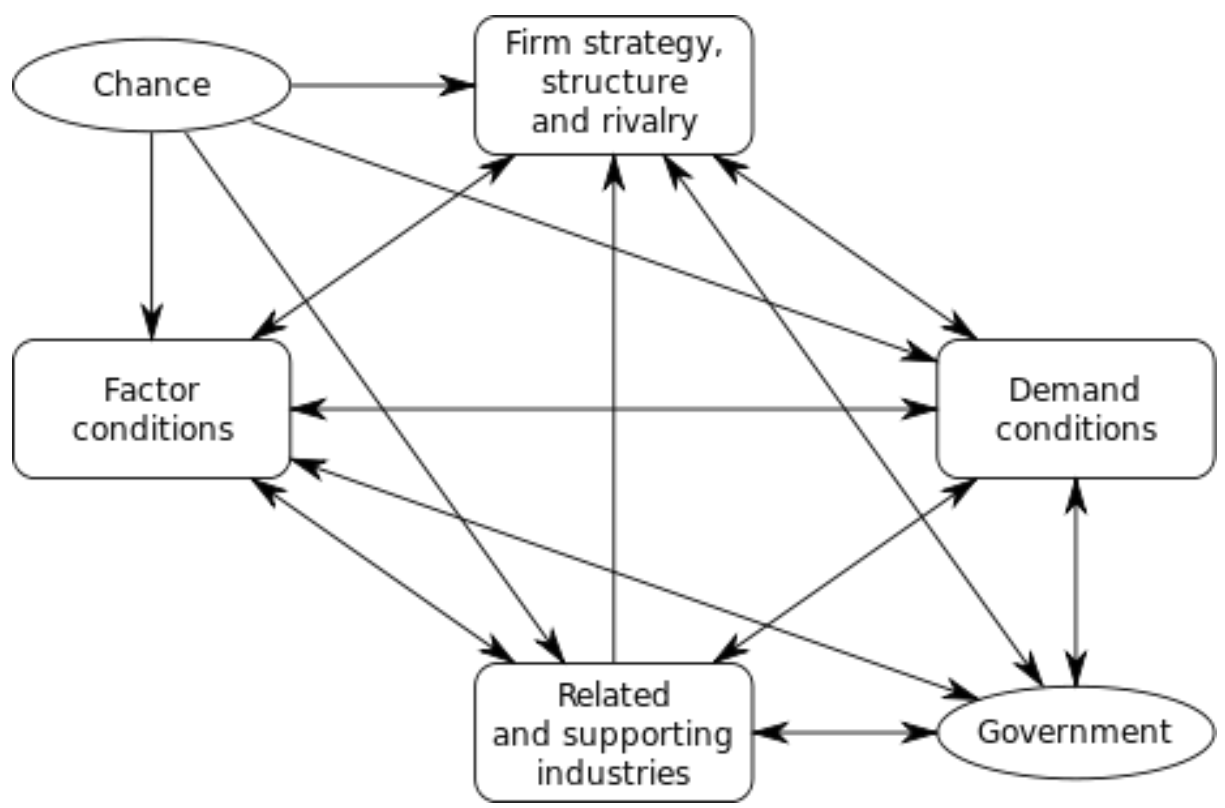

Figure 1. Michael Porter`s Diamond Model

\subsection{Factor Conditions}

On the one hand, the original visual effects were born as an accessory of films, so visual effects industrial clusters tend to be close to location of the film production industry with a certain geographical advantage. The first reason why Hollywood becomes the film center is exactly due to its geographical advantage. Located in the northwest of Los Angeles, California, Hollywood has a unique natural landscape with a mild and agreeable climate with long hours of sunshine, which is very beneficial for filming. Since film industry gathering and rooted in Hollywood, visual effects industry naturally began to form into a certain scale gradually around Hollywood. By contrast, London, as the art center of Europe, has a profound cultural background. Therefore, the majority of British visual effects facilities are London-based and densely concentrated in SOHO. Since Harry Potter series were produced in London, visual effect facilities spontaneously gathered and naturally formed regional industry cluster. Meanwhile, UK has also paid grate efforts on the development of creative industries. SOHO has been seen as the forefront of the creative industry, which provides both art background and cultural atmosphere for the production of visual effects. New Zealand visual effects industry came upon the arena of international competition quickly due to the rise of Weta Digital. It is the unique and magnificent natural scenery in New Zealand that attracted Lord of the Rings series to be filmed there and also contributed to remain the visual effects work to local facilities. Along with the visual effects work of these films, Weta has also rapidly grown into a world-class visual effects facility.

On the other hand, with digitization and elimination of geographic isolation, the publicity of software technology gradually makes the effects production shift the originally high demands on the computer hardware into a technical and artistic requirement for artists. Human resources are the key to international competitiveness for the regional visual effects industry. Since the early effects industry required high threshold for the computer hardware and software technology, Hollywood has been in a position of technical monopoly. Even today, due to the rapid development of technologies, the monopoly of Hollywood no longer exists but decades of accumulated equipment, technology and highly experienced technical personnel are still at the world's highest level. As the art center of Europe, London has been emphasizing creativity in personnel training, and therefore has brought a large number of creative talents with both 
artistic skills and techniques, which undoubtedly provides the manpower for the visual effects production which demands creative and artistic accomplishment increasingly rigorously. New Zealand spared no effort to train and attract talents from all over the world. Weta has artists came from 35 countries. During the production period of Avatar, in addition to absorbing professionals around, students in the specialized schools are also selected for training, which helps New Zealand to contain pluralistic international human resources.

Throughout the development process of the visual effects industry clusters in three regions, the initial reason is the geographical advantage that large budget films were filmed there. It shows that geography advantage near the filming location of large budget film is the key factor to form the early visual effects industry cluster. However, with the great development of the modern network transmission technology, the advantages at the geographic level are gradually weakened. The convenience of the long-distance data transmission allows the post-production of films can be carried out anywhere. Now, under the background of the global industrial division, the creative talent pool with mature technology has become more crucial to competition.

\subsection{Demand Conditions}

Hollywood visual effects industry has been relying on the six film studios. Along with the attraction of favorable exchange rates and tax incentives from other countries, "runaway production" has became an issue in California that plenty of projects left the state to overseas emerges, which obviously impact Hollywood visual effects industry. At the same time, dominating role of the six studios in the US market leads to the imbalance of the power distribution of the industry chain. Fierce competition has forced facilities to lower the production price that results in interests of visual effects facilities being constantly compressed. Compared with Hollywood's crisis, London and Wellington therefore benefit and boom rapidly promoted by Hollywood films, especially New Zealand mainly depends on the high-end Hollywood film markets due to its small domestic market. It is worth noting that such a high degree of dependence on a single market is vulnerable to the impact of external economy or policies. But visual effects industry has a low dependence on the geographical environment, as a result it is also easy to be replaced. The crisis of Hollywood is a warning. When UK is trying to attract Hollywood films, it also paid attention to promote the local film and television industry. Therefore the domestic box office also provides UK with a relatively stable market allocation compared with New Zealand. In summary, in order to maintain a long-term stability of the regional visual effects industry, it is crucial to contain a diversified structure of target markets and expand the local film and television markets while pursuing overseas projects. In order to avoid the imbalance of the power relationship resulting from the film studios, we should try to explore the emerging markets apart from traditional film and television market, and disperse the risk differentiation marketing strategies.

\subsection{Firm Strategy, Structure and Rivalry}

From the lesson of Hollywood's current crisis, in contrast with the gradually mature technology, visual effects industry's business model and philosophy have expose their inherent problems. The current business model which began in the 70s in the post Star Wars is still used today and followed by visual effects facilities around the world. The initial visual effects artists were either hired as the staff for a film project or affiliated to the film's special effects department. After Star Wars, the artists began to set up independent visual effects facilities and also began to invest budgets to technology R\&D. The fixed budget model at that time developed in the 1980s when the techniques and expectations were both highly limited. Although it promoted the technological 
development and satisfied the demand for visual effects, with the rapid development of advanced techniques, the appearance of low-cost software reduced the threshold of visual effects industry and the visual effects facilities increased rapidly. The competition led to the decrease of the production price and the profits of the project gradually shrunk. Meanwhile, in order to ensure the technical advantage in the competition, facilities also need to invest more in technology development and equipment. Because it is unpredictable on the project time and shot requirements, the delay of filming footage or repeated changing request for effect shots from clients would cost a large production expense. Unfortunately, according to the fixed budget contract, film studios do not need to pay for that additional time and work, the visual effects facilities should bear the loss. The unpredictability of project can cause the difficulty of schedule arrangement for facilities, if the facility failed to turn into the next project for certain time, it still had to pay for artists to keep them stay. Thus visual effects facilities are living on projects, the gap between projects would likely lead to the bankruptcy directly resulting from the break capital chain. In addition, visual effects facilities currently provide production services only as their main business philosophy. In order to gain the project, visual effects facilities always distinguish from other facilities through the low-cost, tax preferences, special technology and other aspects. This kind of work-for-hire service model comes with the high risk of the substitutability from other competitors. In spite of having taken the investment risk of both money and time, corresponding benefits cannot be paid back from the film further success. If the facility is unable to provide "additional value", the customers will decide by price only.

Although each part in Hollywood film and television industry chain is relatively mature and each industry species has its own union, visual effects in US still has no such union or industry association to represent the industry interests. When the Rhythm \& Hues` bankruptcy sparked concerns about this industry, more people began to put forward the views of the establishment of trade unions. The loss of industrial trade association exerted a negative impact on both the industrial development and the protection of the rights of artists. Compared to Hollywood, the UK Screen in Britain not only provides several services such as employment information, application for funds, technology training for visual effects artist, but also conveys their views to UK government and influence. As for New Zealand, the New Zealand institute of Screen Innovation(NZISI) consisting of representatives from all digital content facilities, which is responsible for providing an information exchange platform for facilities in New Zealand, as well as the opportunities and project guidance to promote the visual effects industry.

Therefore, for the long-term sustainable development of the industry, it is necessary to change the work-for-hire service model and the fixed budget bidding mode. Effects facilities can enhance facility's additional values through customer service, production efficiency and personal relationships and try to enter the upstream of the production industry chain, wining product market interests as co-producers with the methods like technology investment or joint investment, or change the passive status quo in industries by changing the direction from providing service to creating contents, gradually shifting the focus from mere service provider to the creation of content products. When Digital Domain saw the problems themselves when they were facing the management crisis, and they acknowledged the traditional business model should be changed, so they involved in the production of Ender's Game as a joint-investor. In spite of debt problems, Digital Domain failed to avoid the fate of bankruptcy in the end, they have been trying to change the existing business model to seek for a long-term development. Meanwhile, the assistance at the organizational level that the industry associations provided is indispensable for the development of regional visual effects industry. Based on the geographical concentration of forming industrial cluster and the organizational help from industrial association, it would create a healthy competitive environment of regional industrial cluster and improve the coordinated development of the whole industry. 


\subsection{Related and Supporting Industries}

Film, television, commercials are undoubtedly the main markets that visual effects rely on, especially for the film, a large budget film can even drive the visual effects industry throughout the region. London and New Zealand are the best examples. As a traditional film industry center, Hollywood has had a complete film production chain from writing, planning in pre-production, to location shooting in main-production, until visual effects in post-production, as a mature internal industry environment. With the support of Harry Potter series, SOHO in London now is also capable to complete the whole film project whining the area from concept design till visual effects. What' $\mathrm{s}$ more, as a creative industry center, companies closely related to the visual effects are densely arranged around SOHO, such as film, advertising, design, games, and animation and publishing. Such regional industry cluster environment contributed by content creation provides a network and cultural background for the visual effects industry. Different from Hollywood and London, New Zealand's visual effects industry represented by Weta gets rooted not depending on the local upstream industry but on Hollywood films, and the visual effects has succeed to become the main industry rather than film and television production. Weta Digital gradually expanded their business areas as well, now they have founded sister facilities such as Weta Workshop which was responsible for special effects makeup, Stone Street Studios with studio services and Park Road Postproduction for sound, which aimed to complete the industry chain of the production within the region gradually and thus enhanced the overall international competitiveness based on putting the visual effects as the breakthrough point.

Whether from the Hollywood-way depending on the upstream industry or the Wellington-way rising from the specific industry itself then to the upstream industries gradually, it is not difficult to notice the importance of the related and supporting industries. Since visual effects require the combination of both art and digital techniques, the cultural background of creative arts and business support from related facilities are significant environmental factors for the long-term sustainable development of regional visual effects industry cluster.

\subsection{Government}

Visual effects workers in the United States have long been calling for Congress to intervene on their behalf. But they have had to fight the powerful Motion Picture Association of America's annual lobbying budget of $\$ 4.7$ million. Government behavior also affects the regional industry in various aspects. In Hollywood case, the tax incentives of other regions easily wreck this rugged film empire. It claims that currently tax incentives have become the indispensable basis to maintain the region in the global competition. The Chancellor of the Exchequer of UK has announced a series of support policies for the promotion of VFX industry through "the Autumn Statement 2013". New policies have been implemented from Apr, 2014, and it has increased the rate of tax relief for large budget film from 20 per cent to 25 per cent for the first $£ 20$ million of qualifying production expenditure. And the UK minimum spend threshold has reduced from 25per cent to 10per cent. Furthermore the UK government intends to seek state aid clearance to increase the rate of relief to 25 per cent for all qualifying expenditure when re-notifying film tax relief in 2015. New Zealand has significantly improved the incentives it offers international film and television productions. The improvements came into effect on April 1, 2014 with the introduction of the New Zealand Screen Production Grant, an uncapped grant-based screen incentive backed by the New Zealand Government. The improvements include a new 20 per cent baseline grant for international productions, up from a previous 15 per cent rate. In addition to the new baseline grant, a smaller number of projects may be eligible for an additional 5 per cent if they can demonstrate significant economic benefits to New Zealand. 
On the other hand, it also offered as a cautionary tale for other regions that are only dependent on tax incentives to keep work in their area. No regions have guaranteed incentive support indefinitely, and any number of external economic, social, or political forces could quickly alter the offerings. An area that suddenly fails to offer the best tax incentives could suddenly experience the "runaway production" that Hollywood has suffered, with even bigger consequences if the local industry is not sustainable without incentives.

\subsection{Chance}

Considering the success of all these three areas, the initial support and promotion of large budget films that had provided an significant opportunity for the upgrade of overall industry. Each of these large budget films such as the Star Wars series in Hollywood, Harry Potter series in London and Lord of the Rings series in New Zealand, help to upgrade the scale and technology of the regional visual effects industries in an overall way. In order to attract the large budget films for their visual effects works, all kinds of complex conditions like technical strength, production costs, tax preferences, exchange rates, personal relationships and insurance systems, become uncertain factors which contribute to opportunities ultimately. Therefore, local governments and industry associations should assist facilities by providing an international platform of information exchanges and foreign publicity for the local visual effects industries, and create more opportunities for local enterprises to participate in the international projects.

\section{Conclusion}

Based on the research of the state of global visual effects industry, Hollywood, London and Wellington as the most representative visual effects clusters of the world are selected as the research objects. According to the diamond model of industry cluster, the paper has analyzed the key factors of the success of visual effects cluster by comparing the development progress and their characteristics between these three regions. It has pointed out the current problem in global visual effects and suggested a long-term development strategy for regional visual effects cluster in several aspects: human resources has become the most important condition of this industry rather than traditional geographical advantage; besides film and television market more attention should been paid to explore new contents fields both in domestic and overseas markets; change the business strategy from providing service to creation to entry high value-added part for long-term development; enhance the connection of related industry and combine the industry with regional cultural resources. In additional, supporting policies are playing a very important role than ever as to keep the region in the global competition with others. The organizational assist from industry association is certainly required for representing the rights of regional industry and providing certain help to promote the industry overall, including seeking for the opportunity for large budget film.

\section{Acknowledgements}

This work was supported by the Brain Busan 21 Project in 2014.

\section{References}

[1] "Visual effects: providing further support to the industry," HM Treasury, (2013), pp. 1-19.

[2] "The State of the Global Visual Effects Industry 2013," Visual Effects Society, (2014), pp. 1-52.

[3] Jung-ku Kang, "KOCCA Statistics Briefing”, Korea Creative Content Agency, vol. 13-22, (2013), p. 2.

[4] M. Porter, "The Competitive Advantage of Nations", New York: Free Press, (1990).

[5] J. Herman, "A Brief History of Film Editing Technology”, Editors Guild Magazine, vol. 1, no. 3, (2012).

[6] R. Keegan, "Hollywood's VFX Shops: Trouble in Boom Times," Time, vol. 175, no. 21, special section, (2010), p. 1-2, 2p. 
[7] "A Strategy for the Ontario Digital Animation and Visual Effects Industry", Computer Animation STUDIOS of Ontario, (2010), pp. 70-77.

[8] D. Lu and W. Liang, "The Analysis of the Film and Television Industry Cluster based on Diamond Model", vol. 2, (2012).

[9] P. Yuan, "Activation Plan of the Post-production in China through International Cooperation", Dongseo University, (2013).

[10] P. Yuan, "Research of Brand Strategy for Regional VFX Industry", Korea Multimedia Society, vol. 17, no. 1, (2014).

\section{Authors}

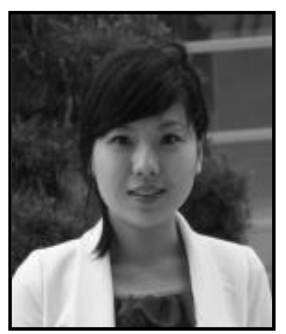

Pinfang Yuan, BFA of Mass Media from Zhongnan University of Economics and Law, Wuhan, China (2011)

MFA from Visual Contents of Dongseo University, Busan, Korea

Ph.D. Course at Division of Visual Contents, Graduate School, Dongseo Univ. Busan, Korea (2013 )

Research interests: Visual Effects, Digital Contents

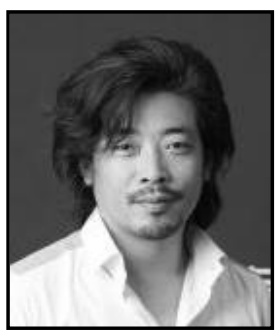

MyungHee Han, BFA of Western Painting from Kyung Hee Unvi. Seoul Korea

MFA of Digital Contents from Kyung Hee Unvi. Seoul Korea

Associate Professor at the Division of Digital Contents, Dongseo Univ. Busan, Korea

Research interests: Visual Effects, Digital Contents

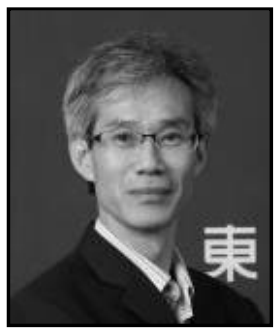

Taesoo Yoon, Ph.D. of Computer Engineering from Kyungpook National Univ. Daegu, Korea (2001)

Researcher for DAEWOO Electronics R and D Center (1993 1998)

Full Professor at the Division of Digital Contents, Dongseo Univ. Busan,

Korea (2001 )

Research interests: Game Development, A.I. 
International Journal of Multimedia and Ubiquitous Engineering

Vol.10, No.4 (2015) 